\title{
Not in Education, Employment or Training: Not in Dietary Health Promotion?
}

\author{
J Robinson and B Stewart-Knox \\ Northern Ireland Centre for Food and Health (NICHE), School of Biomedical Sciences, University of Ulster, \\ Cromore Road, Coleraine, County Londonderry, BT52 ISA, UK
}

As with other marginalised groups, young people not in education, employment or training (NEET) are at risk of adverse health outcomes and have higher rates of overweight and consumption of higher fat/lower fibre foods, compared with similarly-aged college students/ graduates. With having left school early considered a marker of social disadvantage and health inequality, the importance of meaningful engagement with young people on health issues that affect them is essential for successful intervention. There is evidence that tailored provision in the youth sector can achieve very positive outcomes. The primary aim of this study was to gain an understanding of the dietary health promotion needs of young people who are NEET. The objective was to elicit service providers' perspectives on food and nutrition related health issues in various NEET settings within Northern Ireland.

Individual interviews with service providers $(n=6)$ were employed. Qualitative thematic content analysis was undertaken by two analysts who discussed competing themes and sub-themes until consensus was agreed.

Informants indicated a number of barriers faced by young people in achieving healthy lifestyles. Drug use and alcohol consumption was considered a major health problem for the young people. There was also a perceived lack of support and hope for the young people to achieve a healthy lifestyle. Less surprising, money was considered a constraint upon acquisition of healthy food. These data implied that intervention should first seek to alleviate the prevailing problems associated with drug and alcohol use. Informants also implied that young people require an individualised approach to the promotion of healthy eating, one which is needs led and in which they are actively involved. Further the intervention should also seek to provide social support for the young people in achieving healthy lifestyle habits and in doing so, to foster hope. Service providers also highlighted the need for training to equip them with the knowledge required to raise awareness of the impact that these issues appear to have on their young people's lifestyle, was perceived to be immense.

This research has provided an in depth understanding of the nutritional issues of salience to those providing services for NEETs in Northern Ireland and of potential problems in addressing these issues.

This work was funded by safefood, Ireland.

1. McCoy S, Kelly E \& Watson D (2007) School leavers survey report 2006. Dublin: ESRI and Department of Education and Science.

2. Georgiou C et al. (1997) 'Among young adults, college students and graduates practiced more healthful habits and made more healthful food choice that did nonstudents'. Journal of American Dietetic Association 97(7): 754-759.

3. Youth Action NI (2010) Oral and Written Evidence to the DEL Committee Inquiry into Young People Not in Education, Employment or Training, 2 June 2010 - www.niassembly.gov.uk/record/committee2009/EmploymentLearning/100602_NEETS 